\title{
Ergonomics workstation environment toward organisational competitiveness
}

\author{
Zafir Khan Mohamed Makhbul ${ }^{1}$, Md Shafiin Shukor ${ }^{2}$, Ariff Azly Muhamed ${ }^{3}$ \\ ${ }^{1}$ UKM-Graduate School of Business, Universiti Kebangsaan Malaysia, Selangor, Malaysia \\ ${ }^{2}$ Faculty of Economics and Management, Universiti Kebangsaan Malaysia, Selangor, Malaysia \\ ${ }^{3}$ Faculty of Business and Management, Universiti Teknologi MARA, Selangor, Malaysia
}

\begin{abstract}
Article Info
Article history:

Received Oct 6, 2020

Revised Nov 5, 2021

Accepted Nov 19, 2021

Keywords:

Acoustic

Environment

Ergonomic

Job performance

Productivity

ABSTRACT

The lack of comfort due to workplace environment impact could trim down job performance and organizational productivity. Literature reviews indicate that ergonomic workplace environment that is strongly associated with the job performance. Employees' perceptions to be examined by the organizations to ensure the excellent job performance. Thus, 295 officers were selected using proportionate stratified random sampling with twosection questionnaire. The data were analyzed using statistical package for the social sciences (SPSS) and analysis of a moment structure (AMOS) software. The research findings show that acoustic is the most crucial factor (0.928) followed by lighting (0.898), workstation design (0.846), working hours $(0.670)$, and chair $(0.563)$. Ventilation is still significant to the whole environment although scored the lowest coefficient value $(0.385)$. These findings provide valuable information to organizations in their attempts to sustain the human resources so that they are always competitive and productive in facing the challenges of the environmental change.
\end{abstract}

This is an open access article under the CC BY-SA license.

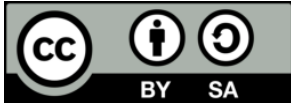

\section{Corresponding Author:}

Zafir Khan Mohamed Makhbul

UKM-Graduate School of Business, Universiti Kebangsaan Malaysia

43600 UKM Bangi, Selangor, Malaysia

email: zafir@ukm.edu.my

\section{INTRODUCTION}

Changes in the business environment and the development of automation technologies as part of Industrial Revolution 4.0 (Industry 4.0) have contributed to the stress problem in most individuals in Malaysia. Developments in literature and mass media exposure show that the stress issue is becoming more significant in today's business environment, organizations and life. The issue of stress needs to be addressed because of its huge impact on the quality of life and welfare. Prolonged stress can trigger many negative implications to occupational health, which will affect the productivity and competitiveness of organizations [1]. Among the causative factors of stress in workers are organizational, family/social, and environmental factors. This was supported and discussed in the study proposing that factors like conflicts with colleagues and superiors also led to the stress among workers [2]. According to them, environmental factors such as loud noise, improper ventilation, dim/insufficient lighting, and uncomfortable workstations also play a crucial role in triggering stress.

It is a fact that a non-ergonomic workstation can cause stress in an organization's employees. Studies have been consistent on this and some stated that the workstation environment such as a hazardous workspace design and noisy surroundings can also cause a person to experience stress at the workplace [3]. Stress is the response of an individual to his or her environmental characteristics [4], [5]. If the individual has a negative perception of his or her work environment, surely the individual will face stress [6]. The physical 
environment of a workstation includes various aspects such as the ventilation system, lighting, workspace design, and acoustic system. Previous studies have also shown that the workplace environment such as extreme temperatures, poor lighting, and a crowded workplace can be a measure of stress at work [7]. The study also discussed the environmental factors that can cause employees to experience stress [8]. The results of their study indicated that the work environment factors require special attention so that stress at the workplace can be addressed. If this problem can be resolved in the early stages, it can minimize employees' overall performance problem.

The effects of ergonomics in the work environment need to be emphasized in an organization as they can affect organizational performance. An awareness of the impact of work processes and technology on humans has led to the ongoing research on ergonomic concepts in achieving organizational goals. Ergonomics is a new field that is constantly changing [9], [10]. The level of ergonomic applications and awareness in many countries is still low despite the enormous impact that ergonomics has on the improvement of work practices and occupational safety and health [9]. There have been many studies that demonstrated the positive effects of the implementation of ergonomic principles at workplaces [11]-[13]. An unergonomic work environment also affects the performance of the organization involved. This is contributed by the fact that employees cannot fully concentrate on their work due to adverse environmental factors such as poor lighting, a noisy environment, uncomfortable chair design, and insufficient ventilation [14].

Some studies have shown that the use of information and communication technology supported by lighting and working hours can cause job stress, especially technostress in workers and organizations. Symptoms of technostress include wrist-related injuries, musculoskeletal disorders, fatigue and exhaustion. It also has an effect on the vision, which can cause physiological and psychological stresses. In addition, the use of gadgets related to computer technology over long working hours can cause a person to experience headaches and difficulty focusing on the work [15], and these are also the causes of stress.

Workstations also have an effect on the level of stress experienced by an employee. There are a few things to keep in mind when designing an efficient and effective workstation. Among the aspects that should be noted are the chair/seat position while working, workspace design, ventilation system, acoustic system, lighting, and working hours. Chairs play an important role in ensuring the comfort of a workstation. Ergonomic chairs can influence an individual's work performance as fatigue and tension can well be avoided [16]-[18]. The traditional workstation layout is no longer compatible with the modern work environment [19]. These changes are in line with the implementation of technology and the impact of changing employees' perceptions of work as well as occupational safety and health. An efficient and effective workstation must have a very comfortable workspace. Furthermore, some of the major causes of stress in an organization are from extreme temperatures and a dusty or dirty environment [20]. Practicing moderation in setting the temperature of an organization is crucial in ensuring a comfortable and productive work environment.

Job stress associated with an ergonomic work environment is an issue that needs to be addressed in gaining organizational competitive advantage. Competitiveness is very important in dealing with changes in the business environment and technological advancements. A lack of competitiveness can affect the sustainability of the organization in achieving its goals. Studies in organizational behavior show that environmental factors (ergonomics) are underestimated by organizations [21]. The study showed further that job stress can occur in any organization and can leave a lasting negative impact [21].

This study on respondents' perceptions of ergonomic environmental factors is consistent with the description of individuals' perceptions of their work environment. The selection of respondents among officials in a government department in Malaysia is appropriate because assessments related to the ergonomic environment in government departments have received little attention from previous scholars. The discussion of this article continues with a discussion of the literature review and theoretical framework, study methodology, analysis and findings. The discussion and conclusions of the study are also included at the end of the article.

\section{LITERATURE REVIEW AND THEORETICAL FRAMEWORK}

Technological advances and changes in the business environment, coupled with competition in today's world have caused occupational stress to be a major health issue presently. In facing the challenging world of competition, there has been too little attention on the impact of the work processes and technologies used [22]. As a result, work processes can be harmful to workers and new technologies being used may not meet the organization's goals to enhance the overall employee efficiency and firm productivity. Environmental factors play an important role in describing occupational stress issues. The environmental factor in question is a work environment that helps employees perform their tasks efficiently and effectively. 
The awareness of the impact of work processes and technology on people has led to ongoing research in ergonomic concepts and stress in the workplace in achieving organizational goals. Compared to other scientific disciplines, ergonomics is relatively new to the society and most people are unaware of the contributions of ergonomics to national well-being and economic development [23]. In Malaysia, ergonomic awareness is still at an early stage due to the limited knowledge of ergonomics [24], [25].

An effective ergonomic environment can reduce work stress in individuals and organizations [26], [27]. The science of ergonomics is a field of study that investigates how to minimize stress at work [28], [29]. An ergonomic workplace design is one of the strategies that organizations can use to minimize stress in the workplace [28], [29]. Therefore, in the process of designing a workstation, several ergonomic factors need to be taken into account [17], [28], [30]. This is because humans differ in their abilities and limitations in terms of their strength, speed and skill.

This phenomenon has alerted researchers to the importance of an ergonomic work environment and its potential for minimizing job stress. There are a few things to keep in mind when designing an efficient and effective workstation environment. Some of the aspects that should be noted are the chairs/seating at work, workspace design, ventilation system, acoustic system, lighting and working hours.

\subsection{Chair/seating at work}

Chairs play an important role in ensuring the comfort of a workstation. Ergonomic chairs can influence an individual's work performance by avoiding fatigue and tension [17], [18]. Adjustable chairs with strategically positioned armrests can minimize the load on shoulder and arm muscles [31]. It can also minimize the tension in the neck area. Studies have shown that there is a relationship between work that requires $95 \%$ of sitting time and the pain in the neck and shoulders [32]. An ergonomic chair design not only enables workers to complete their tasks but also helps to expedite the execution of these tasks [33]. When sitting down, an individual should make sure that the hips maintain an ' $S$ ' shape according to the spine curvature. This position can prevent the pressure on the cartilage and the main function of the hip [33]. Chairs in the context of this study relate to workers' perceptions on ergonomic chairs and the fact that it can influence an individual's work performance by avoiding fatigue and tension.

\subsection{Work area design}

An efficient and effective workstation has a very comfortable work space. These work areas include a comfortable workspace that is crucial in ensuring a smooth workflow and increasing employee productivity. Poor workspace design can be a source of stress in the workplace [7]. Social psychology studies have shown that a congested and crowded workspace can negatively affect an individual's job performance [34]. Research has shown that workspace congestion and discomfort are negatively associated with focus and privacy, which in turn may increase stress in the workplace [35]. Workspace design in the context of this study includes employees' perceptions of the desks, computer equipment and telephones. It covers respondents' perceptions of the working height, screen/monitor, footrests, and flexible armrests and wrist pads.

\subsection{Ventilation system}

An organization's ventilation system also helps to make the employees more productive, and vice versa. If the temperature in the organization is too high, it can increase fatigue and disrupt employees' emotions. If it is too cold, it can cause musculoskeletal disorders and affect employee's health. In addition, some of the major causes of stress in an organization are from extreme temperatures and a dusty or dirty environment [20]. Practicing moderation in setting the temperature in an organization is crucial in ensuring a comfortable and productive work environment. Research in ergonomics has shown that extreme cold and heat, or temperature is negatively associated with the performance and stress levels of individuals [6], [36]. The ventilation system factors that the researchers wish to explore include respondents' perceptions of organizational temperature, air circulation and unpleasant odors.

\subsection{Acoustic system}

An ergonomic workstation environment also takes into account the acoustic aspects in ensuring the comfort and wellbeing of workers. It also enables employees to perform tasks in a focused manner without the noise interruption. Innovative offices need to focus on acoustic aspects and visual stimulation [37]. For this, the office needs to be equipped with acoustic damping devices and equipment that can prevent noise such as providing a glass space between workspaces, acoustic ceilings, printer cabinets, and so on. Noise can be measured by using a decibel measurement unit. Human factor studies have identified that excessive and unexpected noises can affect work performance and cause emotional tension [38]. It can increase blood pressure, hinder sleep, and cause headaches and hypertension [39]. Noise disruption can also cause individuals to lose focus, experience fatigue, lack confidence, affect their relationships with other people, and 
lead to stress at work [40]. Exposure to noise is also strongly associated with heart problems, work absence, fatigue and psychological stress [41], [42]. The acoustic aspect of this environmental factor refers to respondents' perceptions of noise that may affect an individual's focus on completing their tasks. These noises can come from phone conversations, ringing phones, typewriters, road traffic, organizations near a construction site and many others.

\subsection{Lighting system}

Lighting plays an important role in ensuring that tasks are performed efficiently and effectively. Improper lighting is a major contributor to visual discomfort such as eye strain, watery eyes, headaches and blurred vision [40]. If this discomfort persists, it can exert a certain degree of pressure on individuals which can subsequently create stress [40], [43]. In fact, lighting requirements vary within an organization according to the type of work performed and it has a significant relationship with job dissatisfaction [44]. Lighting in the context of this study refers to respondents' perceptions of the lighting system used in an organization. It encompasses respondents' perception of lighting aspects in helping to accelerate the execution of a given task.

\subsection{Working hours}

Working hours need to be taken seriously by an organization to ensure that its human resources can obtain sufficient rest. Working hours that place an importance on adequate rest periods enable the task to be carried out efficiently and effectively. Working long hours without adequate rest can lead to fatigue and can increase stress in an individual [6], [45]. Working hours in the context of this study include respondents' perceptions of the number of working hours, taking into account the overtime and breaks.

\section{THEORETICAL FRAMEWORK OF THE WORKSTATION ENVIRONMENT (BEEHR AND NEWMAN)}

An empirical study model was conducted to assess six aspects of job stress [46]. The general goal of this model is to demonstrate job stress and its relationship with employee health. This model proposes an interaction between the personal and environmental aspects through process aspects that affect both the humanities and organizational aspects. All of these effects will go through the adjustment aspect of minimising the unpleasant effects of work stress. This adaptive response will then re-affect the personal and environmental aspects. All of these processes also depend on the time aspect of the study being carried out. An empirical evaluation of the literature relating to the workplace environment and employee health is performed according to the model in Figure 1. According to the findings by Beehr and Newman [46], many environmental factors have not been investigated by researchers. Therefore, they proposed that the scope of the study be expanded in describing the variables of the work environment (ergonomics) used in the study of occupational stress.

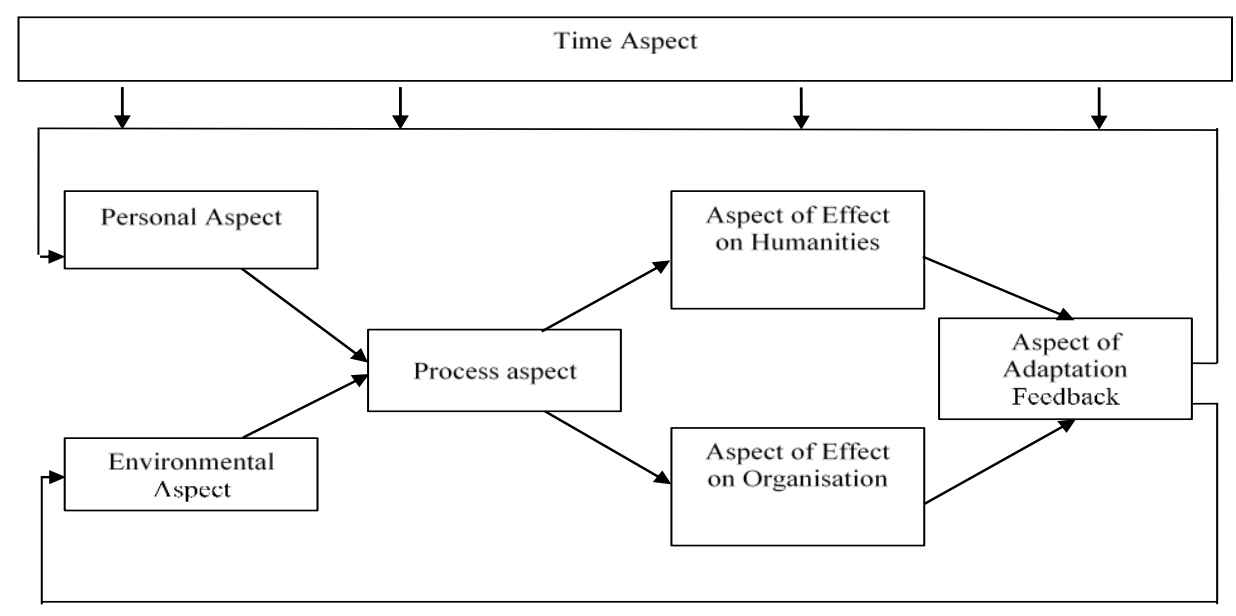

Figure 1. The general model of occupational stress

Based on the explanation and suggestions in the models presented in Figure 1, the researchers have adapted them to form the basis of this research. This research uses aspects of environmental (ergonomic) factors including chair factors, workspace design, ventilation, acoustics, lighting and working hours [47]. 


\section{RESEARCH METHOD}

A total of 696 employees consisting of Grade 41 (71), Grade 44 (303), and Grade 48 (322) officers of both men and women in various units in a government agency in Malaysia constituted the population in this research. However, the sample size of the three Grades was as 295 respondents from Grade 41 (37 people), Grade 44 (139 people) and Grade 48 (119 people). The sample size was calculated according to guidelines with the prevalence of stress placed at 54.6\% [48].

The determination of the sample size was based on the schedule by Krejcie and Morgan [49]. According to the table, when the population size reached 696, the minimum sample size was 155 . Given the large population size and the goal of minimizing sampling errors, this study's sample was fixed at 381 respondents. The sample selection in this study was initiated when the researchers submitted an application to conduct the research to the relevant government agency. Field studies were conducted in the organization on the dates specified. The sample size determination was made according to the formula:

$$
\text { Sample number }=\frac{\text { Number of officers in organisation }}{\text { Total number of employees in the organisation }}=381
$$

Based on the formula, the selection of samples was performed using the simple random sampling method according to the distribution of the specified number. This sample selection is known as probability sampling or specifically proportionate stratified random sampling. The distribution of sample numbers based on strata is more appropriate and representative of a study [50]. Stratified sampling is also an efficient sampling design in that it provides more information based on predefined sample sizes [50]. In this study, after the researchers received the total population of 696 respondents, the size of the sample for each stratum was dependent on the size of the stratum and it was proportionally determined.

For the first stratum i.e. Grade 41 officers the calculation is as:

a. Number of Grade 41 officers: 71

b. Total number of officers: 696

c. Proportionate method for the first stratum sample size: $\frac{71}{696} X 381=39$

For the second stratum i.e. Grade 44 officers the calculation is as:

a. Number of Grade 44 officers: 303

b. Total number of officers: 696

c. Proportionate method second stratum sample size: $\frac{303}{696} X 381=166$

For the third stratum i.e. Grade 48 officers the calculation is as:

a. Number of Grade 48 officers: 322

b. Total number of officers : 696

c. Proportionate method third stratum sample size: $\frac{322}{696} X 381=176$

The total sample size of the three strata according to the preliminary design was 381 respondents. However, the actual feedback received was 295 respondents with Grade 41 comprising of 37 respondents, Grade 44 with 139 respondents and Grade 48 with 119 respondents. This lack of feedback may be due to the respondents being busy with daily tasks and responsibilities especially for the officers in Grades 44 and 48 . However, the responses received from these 295 respondents were quite adequate based on the early calculations of the sample size according to Krejcie and Morgan's table and the number was highly appropriate to perform the following multivariate analysis [49].

\subsection{Research instrument}

The primary source of this study was obtained through a questionnaire form distributed by the researchers with the assistance of the agency's Human Resource Department. Secondary data were obtained through library research. The researchers referred to books, selected peer-reviewed journals, newspaper clippings and relevant printed materials. The development of the items in the questionnaire form was based on the modification of several questionnaires that have been used in the investigation of workstation environment and occupational stress. The formation of items in the ergonomic environment questionnaire was modified from several studies [19], [27], [51], [52] Each item was structured using a 5-point Likert scale in the form of: i) strongly disagree, ii) disagree, iii) uncertain, iv) agree, and v) strongly agree. Respondents were required to choose the answer closest to their perception based on the answer choices provided: 
a. Part 1: Respondent demographics: This section contained questions related to respondents' backgrounds such as monthly income, marital status, gender, age, duration of service, rank/position and number of children. These questions were provided with the answer options. There were eight questions with their corresponding answer choices where the respondents needed to choose from the options provided.

b. Part 2: Environmental factors (ergonomics)

\subsection{Data analysis}

The study used the descriptive statistics methods to analyse the first part. This section assessed the items using a 5-point Likert scale of: i) strongly disagree, ii) disagree, iii) uncertain, iv) agree and v) strongly agree. This section contained 28 questions covering chair components, workspace design, ventilation, acoustics, lighting and working hours. Each positive item was coded as: i) strongly disagree, ii) agree, iii) uncertain, iv) agree, and v) strongly agree.

The descriptive tests consisted of the analyses of the frequency, percentage, mean, and standard deviation values using the statistical package for the social sciences (SPSS) software. For the five-point scale, a mean scale of below 2.5 is considered as 'disagree' and a mean of 2.5 and above is considered as 'agree'. The reliability test was then used to measure the accuracy of the measurements by the study instrument. The lower the error rate of an instrument, the higher the reliability of the instrument where the reliability test rating ranging from 0.0 to 0.49 is weak, 0.5 to 0.69 is moderate, and 0.7 to 1.0 is strong [53]. Reliability testing also uses SPSS software. Next, the study used the analysis of a moment structure (AMOS) software to analyse the model. This model analysis was used to confirm that the theory built in the study was based on several sub-constructs or components. The theory and literature of this study stated that environmental factors (ergonomics) comprised six main constructs namely chairs, workspace design, ventilation, acoustics, lighting and working time.

To test the theory of the first order analysis in Figure 2 and the second order in Figure 3, the confirmatory factor analysis (CFA) method was used. CFA for the first order used a combination of data from the sub-constructs namely chairs, workspace design, ventilation, acoustics, lighting, and working time. The first objective of this stage is to ensure that the basic components of discriminant validity are achieved. Secondly, this section needs to assess whether or not the fitness indexes reach the required level. In the event that the index of compatibility cannot be reached, an observation must be made of the loading factor of each item. The load value must be $\geq 0.40$ and if the item is below this value, the item must be removed. Then, if the required compatibility index cannot be achieved, the modification indexes (MI) need to be run until the compatibility index is reached. The second order, meanwhile, is intended to identify the sub-construct factor from the first order that contributes to the environmental factor (ergonomic) as in the second order.

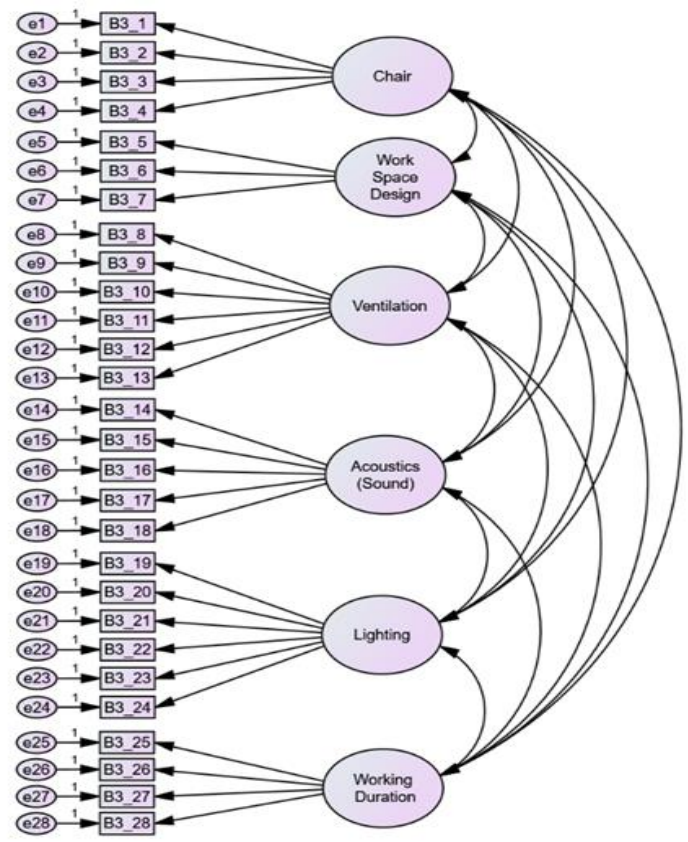

Figure 2. The first order model

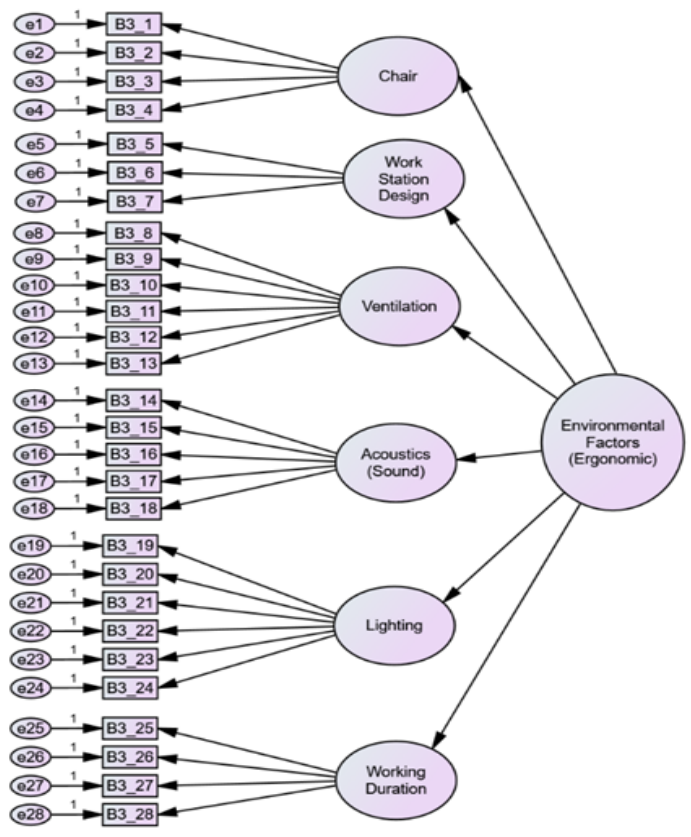

Figure 3. The second order model 


\section{RESULTS AND DISCUSSION}

\subsection{Respondents' demography}

A total of 295 respondents have given their feedback which is then used in the study analysis. In Table 1, there is a clear difference in gender for the respondents of the study. A total of 207 female respondents $(70.2 \%)$ have answered the questionnaire whereas $29.8 \%$ of the male have answered. In terms of the marital status, 224 respondents are married, 58 respondents are still not married, and 13 respondents are divorced. This is followed by $68.1 \%$ comprising of respondents aged between 31 and 40 years old. This shows that the majority of the respondents are in the middle age group. For the category of the designated position, Grade 44 represents is 139 respondents, Grade 48 is 119 respondents and Grade 44 is 37 respondents.

Table 1 also shows that there are four categories of service duration among the respondents. The majority of the respondents have served less than 20 years $(92.5 \%)$. From this $92.5 \%$, 55\% have served between 11 and 20 years. This finding shows that most of the respondents have had quite a long experience with the agency concerned. In line with the grade of the respondents who have answered the questionnaire, the majority of their respondents who answered the questionnaire, have an income from RM3,001 and above (97.3\%). Finally, Table 1 shows that the majority of the respondents have 3 children and below $(80 \%)$.

Table 1. Respondents' demography

\begin{tabular}{|c|c|c|}
\hline Information & Frequency & Percent \\
\hline \multicolumn{3}{|l|}{ Gender } \\
\hline Male & 88 & 29.8 \\
\hline Female & 207 & 70.2 \\
\hline \multicolumn{3}{|l|}{ Marital status } \\
\hline Single & 58 & 19.7 \\
\hline Married & 224 & 75.9 \\
\hline Widower/Widow & 13 & 4.4 \\
\hline \multicolumn{3}{|l|}{ Age (years) } \\
\hline $20-30$ & 16 & 5.4 \\
\hline $31-40$ & 201 & 68.1 \\
\hline $41-50$ & 75 & 25.4 \\
\hline $51-60$ & 3 & 1.0 \\
\hline \multicolumn{3}{|l|}{ Position/Designation } \\
\hline Grade 41 & 37 & 12.5 \\
\hline Grade 44 & 139 & 47.1 \\
\hline Grade 48 & 119 & 40.3 \\
\hline \multicolumn{3}{|l|}{ Duration (years) } \\
\hline$\leq 10$ & 108 & 36.6 \\
\hline $11-20$ & 165 & 55.9 \\
\hline $21-30$ & 19 & 6.4 \\
\hline $31-40$ & 3 & 1.0 \\
\hline \multicolumn{3}{|c|}{ Monthly gross income (RM) } \\
\hline $1501-2000$ & 2 & 0.7 \\
\hline $2001-2500$ & 6 & 2.0 \\
\hline$\geq 3001$ and above & 287 & 97.3 \\
\hline \multicolumn{3}{|l|}{ Number of children } \\
\hline No children & 85 & 28.8 \\
\hline $1-3$ & 151 & 51.2 \\
\hline $4-7$ & 57 & 19.3 \\
\hline $8-11$ & 2 & 0.7 \\
\hline
\end{tabular}

\subsection{The mean analysis and the loading value}

Table 2 shows the mean analysis for the factor chair where two items are at Agree level and two items are at Disagree level. For the factor of work station design, one item is at Agree level and two items are at Disagree level. The factor of ventilation comprises of three items at Agree level and three items at Disagree level. All the items under the factor acoustics (sounds) are at the Agree level. The factor of lighting shows that an item is at Agree level and five items are at Disagree level. Finally, all the items for the factor working duration are at Disagree level. The Agree level achieved in every item stated above shows that the respondents are satisfied with the environmental factors. The Disagree level shows that respondents are not satisfied with the environment factor.

The first order analysis assesses the validity and reliability of the construct. The loading value for every item is tested through pooled-data (CFA) [54]. The items with low values (less than 0.40) will be abolished (Table 2) [55]. The test outcome reveals that there is one item from the factor chair that is abolished. Next, one item from ventilation, three items from acoustics (sound) and one item from working duration are abolished. The analysis outcome for reliability under Cronbach's alpha towards the factor 
(construct) shows that the reliability value fulfills the items accepted which are chair (0.764), work station design (0.719), ventilation (0.762), acoustics (0.602), lighting (0.738), and working duration (0.774).

Table 2. Mean analysis of the environmental factors (ergonomic)

\begin{tabular}{|c|c|c|c|}
\hline Item & Mean & $\begin{array}{l}\text { Standard } \\
\text { deviation }\end{array}$ & Loading \\
\hline \multicolumn{4}{|l|}{ Chair } \\
\hline I can adjust my chair easily & 2.34 & 1.104 & 0.882 \\
\hline My chair can be adjusted in various positions. & 2.62 & 1.209 & 0.732 \\
\hline The chair I am working on while working has comfortable armrests. & 2.34 & 1.024 & 0.514 \\
\hline I am running out of time to complete my work. & 2.65 & 1.049 & $\mathrm{X}$ \\
\hline \multicolumn{4}{|l|}{ Work space design } \\
\hline The arrangement of the work space and seat in my work station is very congested. & 2.58 & 1.169 & 0.476 \\
\hline My work station has a comfortable work space. & 2.11 & 0.982 & 0.645 \\
\hline The surrounding of my work space is satisfactory. & 2.14 & 0.911 & 0.810 \\
\hline \multicolumn{4}{|l|}{ Ventilation } \\
\hline The interior temperature of the organization is very cold. & 2.93 & 1.098 & $\mathrm{X}$ \\
\hline The interior temperature of the organization is very hot. & 2.11 & 0.772 & 0.642 \\
\hline The air movement in the organization is very little. & 2.53 & 0.899 & 0.491 \\
\hline The air in the organization is too dry. & 2.50 & 0.888 & 0.403 \\
\hline There is an unpleasant odor in the air in the organization. & 2.17 & 0.744 & 0.746 \\
\hline The air in the environment or in the organization is stale. & 2.18 & 0.770 & 0.765 \\
\hline \multicolumn{4}{|l|}{ Acoustics (Sound) } \\
\hline The level of noise in my work area is satisfactory. & 2.62 & 1.109 & $\mathrm{X}$ \\
\hline The noise is distracting me against the work I am doing. & 3.08 & 1.232 & 0.605 \\
\hline The environment of my work station does not have any problem with noise. & 2.41 & 1.065 & 0.553 \\
\hline $\begin{array}{l}\text { My organization makes the effort in minimizing the level of noise in the surroundings of my work } \\
\text { station. }\end{array}$ & 2.52 & 0.968 & $\mathrm{X}$ \\
\hline $\begin{array}{l}\text { The sounds of the phone, conversations and the machines in the organization distract me from doing } \\
\text { my work. }\end{array}$ & 2.69 & 1.117 & $\mathrm{X}$ \\
\hline \multicolumn{4}{|l|}{ Lighting } \\
\hline The level of lighting in my work space is satisfactory. & 2.10 & 0.814 & 0.629 \\
\hline The organization prepares a more flexible lighting system. & 2.38 & 0.936 & 0.513 \\
\hline A bright light in the organization increases my work performance. & 2.44 & 0.874 & 0.620 \\
\hline Lighting from the lights and the windows of the organization is slightly dark. & 2.35 & 0.910 & 0.561 \\
\hline The organization always makes sure that I get enough light when I do my work. & 2.50 & 1.043 & 0.747 \\
\hline The lighting we have in the organization is blinding and irritating my eyes. & 2.33 & 0.953 & 0.453 \\
\hline \multicolumn{4}{|l|}{ Working duration } \\
\hline I feel that my working duration is too long. & 2.44 & 0.960 & $\mathrm{X}$ \\
\hline I am happy with the working duration decided by the organization. & 2.04 & 0.923 & 0.738 \\
\hline I am given enough rest in a certain working period. & 2.12 & 0.801 & 0.771 \\
\hline The working duration does not disturb my personal life. & 2.13 & 0.830 & 0.679 \\
\hline
\end{tabular}

\subsection{Measurement model}

After all the items less than 0.40 are abolished, the CFA analysis observes the suitability indices on the first order and the second order. Based on Table 3, the modification indexes (MI) were done to achieve the suitability indexes that can be accepted. MI will show two redundant items or statements that carry the same meaning with the respondents' perspectives. There are three categories of model suitability and the level of acceptance. Firstly, the parsimonious fit or chi square over degree of freedom (CMIN) achieves at least the value of 3 . However, large a sample has the tendency to increase the CMIN value but the value cannot be more than the value of 5 .

Secondly, the absolute fit which is Chi-square becomes the overall measurement of the number of different discreet moment and sample moment. The greater the number of different samples, the greater the Chi-square value, and the stronger the evidence of the null hypothesis. P-value is the probability of obtaining a great difference as it is with the current sample. P-value is aiming to test the hypothesis that the model is suitable and perfect in the population. To measure the suitability of the model, the statistical measurement such as the Chi-square test, the relative Chi-square (Chi-square/degree of freedom) has been used. That means the p-value of the Chi-square depends on the size of the data. If the size is more than 200 then the index is not applicable. Thus, the root mean square error of approximation (RMSEA) index and the root mean square residual (RMR) must be referred to, so as to determine the model fit.

Thirdly, incremental fit namely comparative fix index (CFI), Tucker-Lewis fix index (TFI), normed fix index (NFI) and incremental fix index (IFI) is used to detect the suitability of the data with the model. If the value for the baseline comparisons is more than 0.80 , it shows that the model proposed is significantly suitable with the goodness of fit index (GFI), normed fix index (NFI), relative fix index (RFI), incremental 
fix index (IFI), Tucker-Lewis fix index (TFI), and comparative fix index (CFI). This incremental fit value is between 0 and 1 . The value close to 1 indicates good model.

The measurement of the first order model shows that the estimation results do not show the outcome that can be accepted. After several items are abolished and the modification index performed, this model has achieved a better level. CMIN/DF is 3.199, the RMSEA value needs to be lower than 0.100 (0.086), RMR is 0.077 , GFI is 0.801 , CFI is 0.812 , TFI is 0.783 , IFI is 0.815 , and NF is 0.752 . Meanwhile, the second order model shows that the estimation results are getting better after the modification index is done. CMIN/DF is 3.199, RMSEA is 0.086 , RMR is 0.077 , GFI is 0.828 , CFI is 0.812 , TFI is 0.783 , IFI is 0.815 , and NF is 0.752 . All these values show that the values can be accepted and significantly fit with the study data. The fit indexes' values show the values that can be accepted (Table 3).

Table 3. The measurement suitability index and the model structure

\begin{tabular}{cccccc}
\hline Index & Cutoff value & Reference material & First-order & $\begin{array}{c}\text { First-order } \\
\text { (Modification index) }\end{array}$ & $\begin{array}{c}\text { Second-order } \\
\text { (Modification index) }\end{array}$ \\
\hline CMIN/DF & $\leq 5.00$ & {$[55]$} & 3.827 & 3.199 & 3.199 \\
RMSEA & $\leq 0.100$ & {$[56]$} & 0.098 & 0.086 & 0.086 \\
RMR & $\leq 0.100$ & {$[57]$} & 0.099 & 0.077 & 0.077 \\
GFI & $\geq 0.80$ & {$[58]$} & 0.633 & 0.801 & 0.828 \\
CFI & $\geq 0.80$ & {$[58]$} & 0.661 & 0.812 & 0.812 \\
TFI & $\geq 0.70$ & {$[59]$} & 0.617 & 0.783 & 0.783 \\
IFI & $\geq 0.80$ & {$[58]$} & 0.666 & 0.815 & 0.815 \\
NFI & $\geq 0.70$ & {$[59]$} & 0.596 & 0.752 & 0.752 \\
\hline
\end{tabular}

\subsection{Second order analysis}

Table 4 and Figure 4 show the significant level test for the environment (ergonomic). The analysis outcome shows five factors that have a very important coefficient with a significant value $1 \%(\mathrm{p}<0.001)$. Although the factor ventilation shows the lowest coefficient value (0.31), it is still significant to the environmental dimension as a whole. Table 4 and Figure 4 show that acoustics is the most important factor in the environment (0.928). The following factors are lighting (0.898), work space design (0.846), working duration (0.670), and chair (0.563).

Table 4. Significance/Priority of the factor to the environment

\begin{tabular}{llcccc}
\hline Factor & Estimated standard & Standard deviation & t-Statistics & Significant level \\
\hline Chair & 0.563 & 0.150 & 5.239 & 0.01 \\
Work station design & 0.846 & 0.221 & 7.473 & 0.01 \\
Eentilation & 0.308 & 0.086 & 3.402 & 0.01 \\
Environment & 0.928 & 0.208 & 6.333 & 0.01 \\
& Acoustics & 0.898 & 0.189 & 6.428 & 0.01 \\
& Lighting & -.670 & - & - & 0.01 \\
\hline Working duration & 0.08 &
\end{tabular}

\subsection{Discussion}

The environment of the ergonomic work station is an important strategy of an organization in minimizing the stress in the organization. It can minimize the cost of the organizational management by means of saving the cost of occupational health and human resource management [3]. Studies also state that an ergonomic environmental factor needs to draw the attention of the organization because neglecting it can leave an ongoing negative impact [21]. Thus, this study is very meaningful as employees are able to evaluate the environmental factors that can influence work performance and productivity. If there is a positive assumption made about the environment, the organization can be said to have achieved an ergonomic level in the work station environment. With negative assumptions on the environment, it means that something has to be done in improving the environment and ensuring that organization can sustain in the competition. This is consistent with the statement whereby the work stress is ignited when there is a negative perception on the environment [4], [5].

The mean analysis and the standard deviation show that the factor of working duration is regarded as less satisfactory among the respondents of the study. The reality shows that the development of information technology can cause the working time to become longer. Duties and responsibilities can be done wherever we are, be it at home or at the work station. Thus, it is not surprising that most employees who should be working in the time stipulated can continue working wherever they are. This technological access 
can make it easier for individuals to be contacted by the supervisor or colleagues without counting the days. This long period of working time can increase the level of stress among individuals [6].

The AMOS analysis shows that these factors are accurate in elaborating the environmental dimension that is ergonomic. AMOS analysis shows that the most important environmental factor assumed by the respondents is the acoustics. If we look at the demography of the respondents in terms of the gender, marital status and age, it shows that the noise can become distracting to the work done. The background of the respondents' demography also shows that they regard it as important to have a peaceful working environment which is far from the noisy environment. This is consistent with the previous works done by several researchers [38], [39] They state that a weak acoustics system can affect one's attention and increase his or her psychological pressure. Additionally, the current office's interior scenario that is more innovative is equipped with sound-proof system and something similar [37].

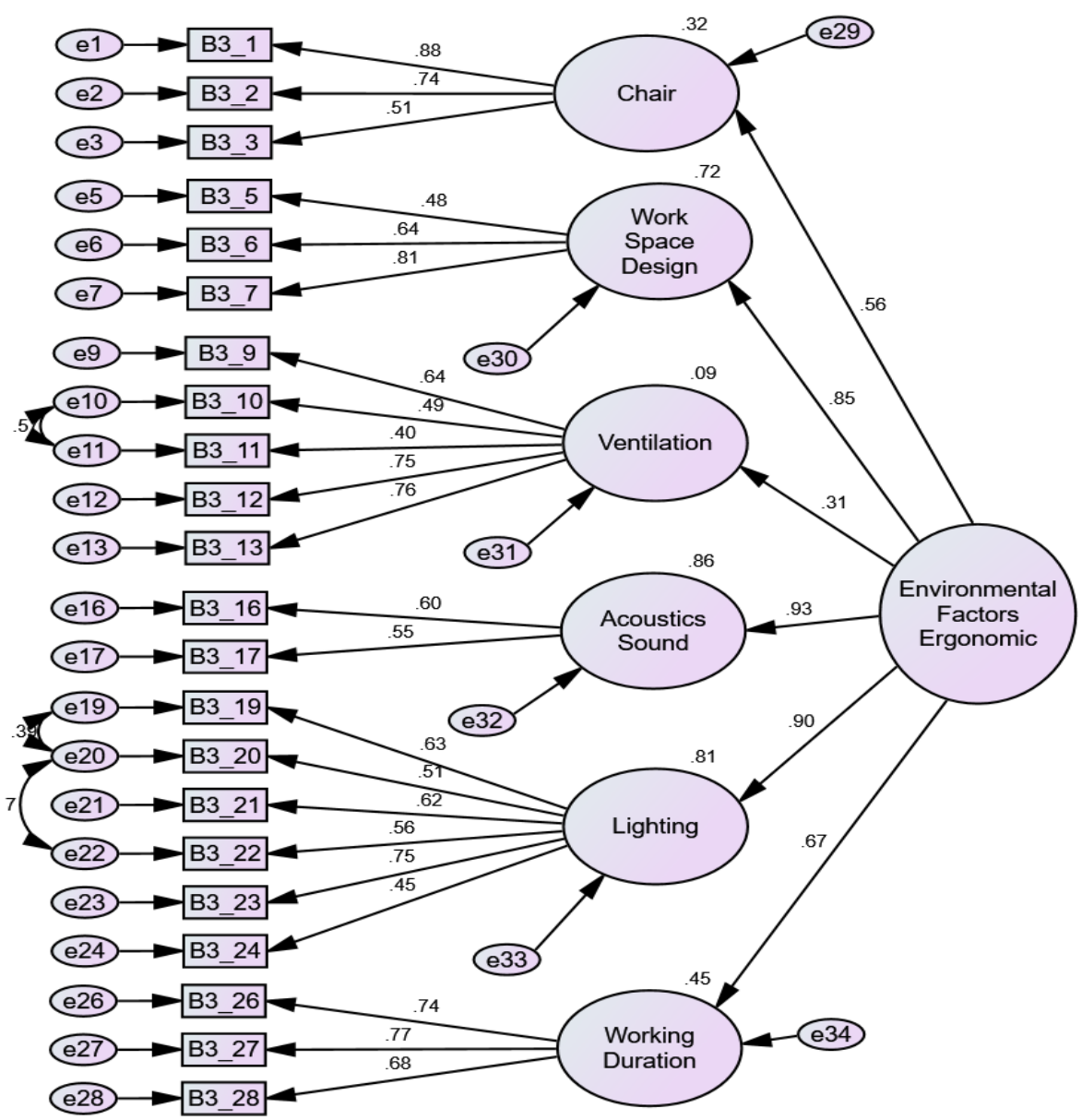

Figure 4. The second order output model

An important factor of the environment is lighting. Unsatisfactory lighting can influence work performance and the level of health of individuals. This is consistent with the statement made by a researcher concerning eyesight discomfort as the lighting system can affect one's health level [40]. If there is an ongoing discomfort towards the lighting system, it can elevate individuals' level of stress [41]. The factor of work space design also plays an important role when respondents see this as the third important factor in the work environment. A comfortable work space can make the tasks more effectively done and make employees more productive. The study states that work space can influence the smoothness of the tasks and productivity [7]. The following environmental factor thought to be important by the respondents is the working duration. As explained in the finding of the mean analysis, this working duration is also important to the organization to ensure that the employees get enough rest to enable them to perform their duties efficaciously and effectively. Working in a long time in the era of information technology and its growth can increase the level 
of stress among individuals [6], [45]. AMOS analysis also shows that the factor of chair is another important aspect in an ergonomic working environment. An uncomfortable chair can cause various health implications and affect individual productivity. This situation has been elaborated by previous scholars [17], [18] They assert that an ergonomic chair can influence the work performance of individuals. Looking at the background of the demography of the respondents, it is reasonable to conclude that the chair is an important factor in the work station environment.

The AMOS analysis also shows that although the ventilation factor shows the lowest coefficient value, it is still significant to the environmental dimension as a whole. Possibly for the respondents of this study, this factor is not prioritized because the organization has a highly satisfactory ventilation system. For them, their superior's actions in preparing for satisfactory air-conditioning system and good air ventilation have led the respondents to fail to see that this factor is prioritized in the environment. Past researchers have stated that the ventilation is very important in the environment because it can influence individual performance and stress [6], [36].

\section{CONCLUSION}

Overall, the findings of this research are crucial in determining the most significant ergonomic work environment factors perceived by employees in ensuring that their tasks are performed efficiently and effectively. This perception is essential towards ensuring healthy and competitive human resources in line with the goal of developing a dynamic human capital. All in all, the outcome of this research is very meaningful to an organization that seeks to ensure that its human resource is in a very good health condition. The declining health condition of the human resource will surely increase organizational costs and affect competitiveness. Such a situation needs to be avoided in the globalized era where competition is increasingly rife and more aggressive. A healthy and competitive human resource is very much required in facing the challenges of the environmental change.

\section{ACKNOWLEDGEMENTS}

This research is supported by Research University Grant Scheme, Universiti Kebangsaan Malaysia (Project Code: PP-GSB-2021 and GUP/2020/001).

\section{REFERENCES}

[1] M. Naveed and H. D. Ramakrishna, "Work stress analysis among workers in the organization," International Journal for Scientific Research \& Development, vol. 4, no. 6, pp. 882-885, 2016.

[2] C. L. Cooper and J. C. Quick, Eds., The handbook of stress and health. Chichester, UK: John Wiley \& Sons, Ltd, 2017.

[3] M. Khandan, S. Momenyan, M. Khodabandeloo, and A. Koohpaei, "Relationship between job stress and ergonomic behavior with musculoskeletal disorders in an auto-part production company," Archives of Hygiene Sciences, vol. 7, no. 1, pp. 23-31, Jan. 2018, doi: 10.29252/archhygsci.7.1.23.

[4] C. Dowden and C. Tellier, "Predicting work-related stress in correctional officers: A meta-analysis," Journal of Criminal Justice, vol. 32, no. 1, pp. 31-47, Jan. 2004, doi: 10.1016/j.jcrimjus.2003.10.003.

[5] B. F. Piko, "Burnout, role conflict, job satisfaction and psychosocial health among Hungarian health care staff: A questionnaire survey,” International Journal of Nursing Studies, vol. 43, no. 3, pp. 311-318, Mar. 2006, doi: 10.1016/j.ijnurstu.2005.05.003.

[6] C. D. Wickens, J. G. Hollands, S. Banbury, and R. Parasuraman, Engineering psychology and human performance, 4th Editio. East Sussex: Psychology Press, 2015.

[7] R. I. Sutton and A. Rafaeli, "Characteristics of work stations as potential occupational stressors," Academy of Management Journal, vol. 30, no. 2, pp. 260-276, Jun. 1987, doi: 10.2307/256273.

[8] J. Nekoranec and M. Kmosena, "Stress in the workplace-sources, effects and coping strategies," Review of the Air Force Academy, vol. 1, no. 28, pp. 163-170, 2015.

[9] R. Ahasan and S. B. Bin Mohamed, "The tasks of individuals practicing human factors and ergonomics," Journal of Ergonomics, vol. 6, no. 4, p. 157, 2016, doi: 10.4172/2165-7556.1000e157.

[10] R. Ahasan and D. Imbeau, "Who belongs to ergonomics? An examination of the human factors community," Work Study, vol. 52, no. 3, pp. 123-128, Jun. 2003, doi: 10.1108/00438020310471917.

[11] B. Das, "An ergonomic approach to designing a manufacturing work system," International Journal of Industrial Ergonomics, vol. 1, no. 3, pp. 231-240, May 1987, doi: 10.1016/0169-8141(87)90017-5.

[12] J. O. Crawford et al., "Musculoskeletal health in the workplace," Best Practice and Research: Clinical Rheumatology, vol. 34, no. 5, p. 101558, Oct. 2020, doi: 10.1016/j.berh.2020.101558.

[13] M. Ramaganesh, R. Jayasuriyan, T. Rajpradeesh, S. Bathrinath, and R. Manikandan, "Ergonomics hazard analysis techniques- A technical review," Materials Today: Proceedings, vol. 46, pp. 7789-7797, 2021, doi: 10.1016/j.matpr.2021.02.329.

[14] Z. M. Makhbul, "Ergonomics workstation: Remedies to minimise stress at the workplace," in Impak Kongres 2015@UKM, 2015, pp. 59-60.

[15] Z. M. Makhbul, “Teknostres in industri 4.0,” Sinar Harian. p. 12, 2018.

[16] Z. M. Makhbul, Ergonomik and Stres in Malaysia. Bangi: Penerbit UKM, 2012.

[17] D. Bossen, "A smarter way to sit," Occupational Health \& Safety (Waco, Tex.), vol. 75, no. 4, pp. 104-106, Apr. 2006.

[18] S. Wilks, M. Mortimer, and P. Nylén, "The introduction of sit-stand worktables; aspects of attitudes, compliance and satisfaction," Applied Ergonomics, vol. 37, no. 3, pp. 359-365, May 2006, doi: 10.1016/j.apergo.2005.06.007. 
[19] A. Nag and P. K. Nag, "Do the work stress factors of women telephone operators change with the shift schedules?," International Journal of Industrial Ergonomics, vol. 33, no. 5, pp. 449-461, May 2004, doi: 10.1016/j.ergon.2003.11.004

[20] D. Rollinson, Organizational behavior and analysis: An integrated approach, 3rd ed. London: Pearson Education, 2005.

[21] J. R. D. Legaspi, C. A. Molanida, R. J. P. Molina, and L. C. B. Pescador, "Work stress and job satisfaction of teachers in Candon National High School," Department of Education. 2017.

[22] D. L. Goetsch, Occupational safety and health for technologists, engineers, and managers, 9th ed. New Jersey: Pearson Education, Inc, 2019.

[23] H. Shahnavaz, "The ergonomics society society's lecture 1995 making ergonomics a world-wide concept," Ergonomics, vol. 39, no. 12, pp. 1391-1402, Dec. 1996, doi: 10.1080/00140139608964559.

[24] V. C. H. Chan, G. B. Ross, A. L. Clouthier, S. L. Fischer, and R. B. Graham, "The role of machine learning in the primary prevention of work-related musculoskeletal disorders: A scoping review," Applied Ergonomics, vol. 98, p. 103574, Jan. 2022, doi: 10.1016/j.apergo.2021.103574.

[25] L. Benos, A. Bechar, and D. Bochtis, "Safety and ergonomics in human-robot interactive agricultural operations," Biosystems Engineering, vol. 200, pp. 55-72, Dec. 2020, doi: 10.1016/j.biosystemseng.2020.09.009.

[26] M. S. Denadai, S. R. Alouche, D. P. Valentim, and R. S. Padula, "An ergonomics educational training program to prevent workrelated musculoskeletal disorders to novice and experienced workers in the poultry processing industry: A quasi-experimental study," Applied Ergonomics, vol. 90, p. 103234, Jan. 2021, doi: 10.1016/j.apergo.2020.103234.

[27] L. Gualtieri, E. Rauch, and R. Vidoni, "Emerging research fields in safety and ergonomics in industrial collaborative robotics: A systematic literature review," Robotics and Computer-Integrated Manufacturing, vol. 67, p. 101998, Feb. 2021, doi: 10.1016/j.rcim.2020.101998.

[28] M. K. J. Khan, A. A. Yusof, and N. A. Chew, Occupational safety and health in organisations. Selangor: Prentice Hall/Pearson Malaysia, 2005

[29] M. Sheikhalishahi, L. Pintelon, and A. Azadeh, "Human factors in maintenance: a review," Journal of Quality in Maintenance Engineering, vol. 22, no. 3, pp. 218-237, Aug. 2016, doi: 10.1108/JQME-12-2015-0064.

[30] C. Drewitz-Chesney, "Posttraumatic stress disorder among paramedics," Workplace Health \& Safety, vol. 60, no. 6, pp. 257-263, Jun. 2012, doi: 10.1177/216507991206000605.

[31] C. Cook, R. Burgess-Limerick, and S. Papalia, "The effect of wrist rests and forearm support during keyboard and mouse use," International Journal of Industrial Ergonomics, vol. 33, no. 5, pp. 463-472, May 2004, doi: 10.1016/j.ergon.2003.12.002.

[32] J. Wahlström, "Ergonomics, musculoskeletal disorders and computer work," Occupational Medicine, vol. 55, no. 3, pp. 168-176, May 2005, doi: 10.1093/occmed/kqi083.

[33] W. Kim, B. Jin, S. Choo, C. S. Nam, and M. H. Yun, "Designing of smart chair for monitoring of sitting posture using convolutional neural networks," Data Technologies and Applications, vol. 53, no. 2, pp. 142-155, 2019, doi: 10.1108/DTA-032018-0021.

[34] E. Garland, A. Watts, J. Doucette, M. Foley, A. Senerat, and S. Sanchez, "Stand up to work: assessing the health impact of adjustable workstations," International Journal of Workplace Health Management, vol. 11, no. 2, pp. 85-95, Apr. 2018, doi: 10.1108/IJWHM-10-2017-0078.

[35] P. A. Jensen and T. J. M. van der Voordt, "Healthy workplaces: what we know and what else we need to know," Journal of Corporate Real Estate, vol. 22, no. 2, pp. 95-112, Jul. 2020, doi: 10.1108/JCRE-11-2018-0045.

[36] A. Feige, H. Wallbaum, M. Janser, and L. Windlinger, "Impact of sustainable office buildings on occupant's comfort and productivity," Journal of Corporate Real Estate, vol. 15, no. 1, pp. 7-34, Mar. 2013, doi: 10.1108/JCRE-01-2013-0004.

[37] E. M. de Croon, J. K. Sluiter, P. P. F. M. Kuijer, and M. H. W. Frings-Dresen, "The effect of office concepts on worker health and performance: A systematic review of the literature," Ergonomics, vol. 48, no. 2, pp. 119-134, Feb. 2005, doi: $10.1080 / 00140130512331319409$.

[38] R. Appel-Meulenbroek, T. van der Voordt, R. Aussems, T. Arentze, and P. Le Blanc, "Impact of activity-based workplaces on burnout and engagement dimensions," Journal of Corporate Real Estate, vol. 22, no. 4, pp. 279-296, Jul. 2020, doi: 10.1108/JCRE-09-2019-0041.

[39] L. S. Greenberg, "Emotion-focused therapy," Clinical Psychology \& Psychotherapy, vol. 11, no. 1, pp. 3-16, Jan. 2004, doi: 10.1002/cpp.388.

[40] R. Blonna, Coping with stress in a changing world. New York: McGraw Hill Higher Education, 2005.

[41] R. Appel-Meulenbroek, S. Steps, R. Wenmaekers, and T. Arentze, "Coping strategies and perceived productivity in open-plan offices with noise problems," Journal of Managerial Psychology, vol. 36, no. 4, pp. 400-414, Apr. 2020, doi: 10.1108/JMP-092019-0526.

[42] R. Mateo, J. R. Hernández, C. Jaca, and S. Blazsek, "Effects of tidy/messy work environment on human accuracy," Management Decision, vol. 51, no. 9, pp. 1861-1877, Nov. 2013, doi: 10.1108/MD-02-2013-0084.

[43] S. L. McShane and M. A. Von Glinow, Organizational behavior, 3rd ed. New York: McGraw-Hill Companies, Inc, 2005.

[44] J. A. Wagner and J. R. Hollenbeck, Organizational behavior: Securing competitive advantage, 4th ed. California: Harcourt College Publishers, 2002.

[45] F. Green, "It's been a hard day's night: The concentration and intensification of work in late twentieth-century Britain," British Journal of Industrial Relations, vol. 39, no. 1, pp. 53-80, Mar. 2001, doi: 10.1111/1467-8543.00189.

[46] T. A. Beehr and J. E. Newman, "Job stress, employee health, and organizational effectiveness: A facet analysis, model, and literature review," Personnel Psychology, vol. 31, no. 4, pp. 665-699, Dec. 1978, doi: 10.1111/j.1744-6570.1978.tb02118.x.

[47] M. Babapour Chafi, M. Harder, and C. Bodin Danielsson, "Workspace preferences and non-preferences in Activity-based Flexible Offices: Two case studies," Applied Ergonomics, vol. 83, p. 102971, Feb. 2020, doi: 10.1016/j.apergo.2019.102971.

[48] R. Selvakumaran, "A study of the prevalence of work stress among prison officers in a prison, Malaysia: A comparison between the results of 2000 and 2003 studies," Universiti Kebangsaan Malaysia, 2003

[49] R. V Krejcie and D. W. Morgan, "Determining sample size for research activities," Educational and Psychological Measurement, vol. 30, no. 3, pp. 607-610, Sep. 1970, doi: 10.1177/001316447003000308.

[50] U. Sekaran and R. Bougie, Research methods for busines: A skill-building approach, 8th ed. New Jersey: John Wiley \& Sons, Inc, 2019.

[51] A. K. Miles, "The ergonomics and organizational stress relationship," Thesis, Florida State University, 2001.

[52] W. A. Hedge, Alan; Erickson, "Study of indoor environment and SBS complaints in air conditioned offices: Benchmarks for facility improvement," International Journal of Facilities Management, vol. 1, no. 4, pp. 185-192, 1997.

[53] R. Kumar, Research methodology: A step-by-step guide for beginners. California: Sage Publications Limited, 2019.

[54] B. Bryne, Structural Equation Modeling with AMOS: Basic Concepts, Applications, and Programming, 2nd ed. New York:

Int J Public Health Sci, Vol. 11, No. 1, March 2022: 157-169 
Routledge/Taylor \& Francis Group, 2010.

[55] J. Hulland, "Use of partial least squares (PLS) in strategic management research: A review of four recent studies," Strategic Management Journal, vol. 20, no. 2, pp. 195-204, Feb. 1999, doi: 10.1002/(sici)1097-0266(199902)20:2<195::aidsmj13>3.0.co;2-7.

[56] M. W. Browne and R. Cudeck, "Alternative ways of assessing model fit," Sociological Methods \& Research, vol. 21, no. 2, pp. 230-258, Nov. 1992, doi: 10.1177/0049124192021002005.

[57] P. M. Bentler, EQS structural equations program manual. Encino. California: Multivariate Software, Inc., 1995.

[58] G. E. Gignac, "Partial confirmatory factor analysis: Described and illustrated on the NEO-PI-R," Journal of Personality Assessment, vol. 91, no. 1, pp. 40-47, Jan. 2009, doi: 10.1080/00223890802484126.

[59] Bollen, "Structural equations with latent variables," New York: Wiley, pp. 1-9, 1989.

\section{BIOGRAPHIES OF AUTHORS}

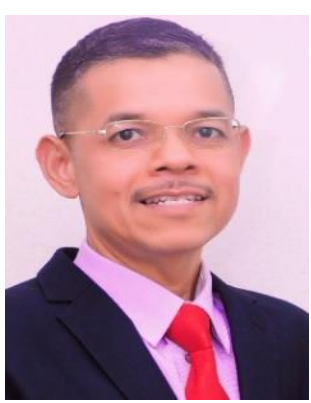

Zafir Khan bin Mohamed Makhbul (D) If SC P a Professor at UKM-Graduate School of Business and Faculty of Economics and Management, Universiti Kebangsaan Malaysia. He has over 20 years of teaching and research experience with Universiti Kebangsaan Malaysia (UKM). He obtained his Bachelor of Business Administration from Universiti Utara Malaysia, Master of Business Administration from Universiti Kebangsaan Malaysia and $\mathrm{Ph} . \mathrm{D}$ in Management from Universiti Teknologi Malaysia. He spent over 20 years of researching, writing and lecturing on the theme "Organisational Management and Human Resource Management” in Malaysia. He can be contacted at ezafir@ukm.edu.my.

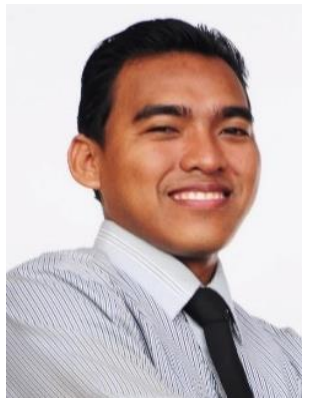

Md Shafiin Shukor (iD SII SC P is a researcher at the Faculty of Economics and Management (FEP), Universiti Kebangsaan Malaysia (UKM). He has completed his Bachelor, Master and Ph.D (Economics) at FEP, UKM in the field of environmental economy, tourism and natural resource. $\mathrm{He}$ can be contacted at email: p80550@siswa.ukm.edu.my.

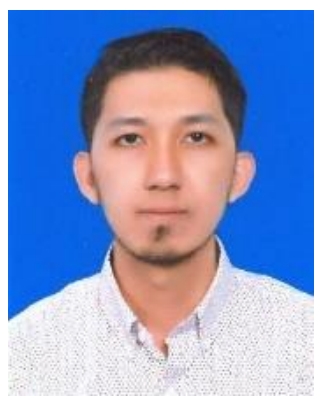

Ariff Azly Muhamed (D) SC P is a Senior Lecturer in Faculty of Business and Management, Universiti Teknologi MARA (UiTM). He obtained his Bachelor of Sciene from Universiti Malaysia Sabah (UMS), Master of Science and Doctor of Philosophy from Universiti Kebangsaan Malaysia (UKM). His research focuses are mainly in Supply Chain Management, Circular Economy, Strategic Management, and Quantitative Study. He can be contacted at email: ariff@uitm.edu.my. 